\title{
REELABORANDO O VIVER: O PAPEL DO GRUPO NO COTIDIANO DE MULHERES IDOSAS
}

\author{
Redrawing the living: the role of groups in the quotidian of elderly women \\ Rediseñando el vivir: el papel de los grupos en el cotidiano de mujeres ancianas
}

Donizete Vago Daher ${ }^{1}$

Kamila Vallory Debona ${ }^{2}$

\begin{abstract}
RESUMO
Objetiva-se compreender a motivação que impulsiona mulheres idosas a procurarem grupos de convivência, analisar e pontuar a apreensão de estratégias que contribuam para a reelaboração e reinvenção de saberes e fazeres em seus cotidianos. Estudo descritivo-exploratório com abordagem qualitativa realizado durante o primeiro semestre de 2007, com 14 mulheres de 60 anos ou mais, participantes há mais de 1 ano do grupo de convivência para idosos denominado Projeto Gugu, ofertado na cidade de Niterói/RJ. 0 trabalho de campo efetivou-se por meio de observação participante e de entrevistas. Os dados gerados possibilitaram a produção de categorias que expressam a significância do grupo como cenário de redimensionamento do processo de envelhecimento, de resgate e ampliação da sociabilidade e de vínculos afetivos. Conclui-se que cenários como o estudado podem recriar formas de conceber e viver o envelhecimento, tornando-o ativo e alargando a possibilidade de inclusão social.
\end{abstract}

Palavras-chave: Envelhecimento. Mulheres. Idoso. Relações Interpessoais

\begin{abstract}
It aims to understand the motivation that drives elderly women to seek support groups, analyze and score the seizure of strategies that contribute to the redevelopment and reinvention of knowledge and practices in their daily lives. A descriptive and exploratory qualitative approach performed during the first half of 2007, with 14 women aged 60 years or more, participants for more than 1 year of support group for seniors called Project Gugu, offered in the city of Niterói, RJ. The field work was accomplished through participant observation and interviews. Data generated enabled the production of categories that express the significance of the group as a setting for resizing of the aging process, of recovery and expansion of sociability and bonds. It is concluded that as the scenarios studied can recreate forms of design and the aging, making it active and expanding the possibility of social inclusion.
\end{abstract}

Key Words: Aging. Women. Aged. Interpersonal Relations

\section{Resumen}

El objetivo es comprender la motivación que impulsa a las mujeres mayores a buscar grupos de apoyo, analizar y puntuar la toma de estrategias que contribuyan a la reconversión y la reinvención de conocimientos y prácticas en sus vidas cotidianas. Estudio descriptivo-exploratorio con enfoque cualitativo realizado durante el primer semestre de 2007, con 14 mujeres de 60 años o más, participantes de más de 1 año de grupo de apoyo para la tercera edad llamado Proyecto Gugu, ofrecido en la ciudad de Niterói, RJ. El trabajo de campo se llevó a cabo a través de la observación participante y entrevistas. Los datos obtenidos permitieron la producción de las categorías que expresan la importancia del grupo como una configuración para redimensionar el proceso de envejecimiento, de recuperación y expansión de la sociabilidad y lazos afectivos. Concluye-se que, los escenarios estudiados pueden volver a crear formas de diseño y el envejecimiento, lo que activa y amplía la posibilidad de la inclusión social.

Palabras clave: Envejecimiento. Mujeres. Anciano. Relaciones Interpersonales

'Doutora em Saúde Coletiva pela Universidade Estadual de Campinas - UNICAMP/SP; Professora Adjunta, lotada no Departamento de Enfermagem Médico Cirúrgica da Escola de Enfermagem Aurora de Afonso Costa da Universidade Federal Fluminense situada na cidade de Niterói - RJ. Brasil. E-mail: donizete@predialnet.com.br,2Pós-Graduanda ao nível de Especialização, sob a forma de treinamento em serviço, nos moldes de Residência em Enfermagem Médico Cirúrgica/Cardiologia, pela Universidade Federal do Estado do Rio de Janeiro - UNIRIO/RJ, exercendo suas funções no Instituto Nacional de Cardiologia, situado na cidade do Rio de Janeiro-RJ. Brasil. E-mail: kamilinhavallory@yahoo.com.br 


\section{INTRODUÇÃO}

Nas sociedades ocidentais contemporâneas, estando aí incluído o Brasil, o envelhecimento populacional é um fenômeno comprovado e que passou a ser um problema social, face às múltiplas demandas que dele advém. " 0 aumento do número de idosos no país vem acompanhado, concomitantemente, pelo acelerado aumento da expectativa de vida, passando aproximadamente de 34 anos em 1900 para mais de 68 anos em 2000, com projeção de alcançar o patamar de 75 anos em 2025."

0 envelhecimento é entendido como "um processo cumulativo, irreversível, universal, não patológico, de deterioração de um organismo maduro e que pode incapacitar o indivíduo para o desenvolvimento de algumas atividades". 2:12

As características identificadoras de processos de envelhecimento de sociedades ocidentais contemporâneas possuem singularidades. Uma publicação brasileira de 2004 chama atenção para o fato de que " [...] o número de pessoas com 60 anos ou mais compreende 302 milhões de mulheres e 247 milhões de homens". ${ }^{3}$ Esta predominância de mulheres no grupo social dos idosos é conhecida entre os pesquisadores da temática de "processo de feminização do envelhecimento". ${ }^{4}$

Rememorando a trajetória das mulheres na história foi possível constatar que, ao realizarem movimentos por ocupação de espaços concebidos como exclusivamente de homens, as mulheres acabaram por expor-se a diferentes jornadas de trabalho geradoras de ganhos, mas que podem, também, representar comprometimentos físicos e psíquicos, uma vez que às atividades antes realizadas outras foram acrescidas, gerando, por exemplo, repetidos quadros de estresse. $^{4}$

Os fazeres hoje compreendidos, também, como de domínio feminino galgaram esse patamar após muitos embates ao longo da história, garantindo atualmente às mulheres direitos antes limitados ao domínio masculino. 0 movimento feminista iniciado na década de sessenta criou bases que despertaram nas mulheres o desejo de revisão e transformação da realidade até então vivida. Deste modo, foi a partir deste período que a procura pelo mercado de trabalho pelas mulheres se intensificou, traduzindo-se em um grande marco para a independência pessoal e para a realização profissional. ${ }^{5-6}$

Este movimento empreendido pelas mulheres, cujo norte era a conquista de mais espaço e reconhecimento sociais, foi gerador de uma reconfiguração de papéis até então vigentes, revestindo-as de nova roupagem. Assim com os papéis de mulher-mãe, mulher-esposa, mulher-do-lar, mulher-do-espaçoprivado, mulher-cuidadora passam a também coexistir os de mulher-profissional, mulher-do-espaço-público. Aos pontos considerados positivos desta conquista são acrescidos outros menos positivos como a escassez de tempo para o cuidado de si. À sobreposição de papéis passam a entrar em cena problemas de ordem física e psíquica. ${ }^{7}$
Um outro ponto que merece destaque relaciona-se a determinantes de processos de exclusão social. No Brasil, determinados grupos sociais como os de homossexuais, de velhos, de mulheres, de doentes mentais, de ex-prisioneiros, por exemplo, convivem, uns de forma mais assertiva que outros, com estereótipos e exclusões que os posicionam na margem, fato que os acompanha em sua trajetória de vida. As mulheres idosas, objeto deste estudo, também são exemplos que sofrem este tipo de exclusão social, uma vez que convivem com um duplo pré-conceito: o de ser mulher e idosa. Essa realidade é geradora de constrangimentos que muitas vezes as impelem de lançar-se em atividades que poderiam Ihes proporcionar prazer. Exemplos que clareiam este fato seria o de aprender a guiar automóvel ou um novo idioma após os 60 anos. Assim, a grande maioria delas naturaliza estas concepções, não realizando o estranhamento que poderia lançá-las para além do vivido. ${ }^{8}$

A fim de amenizar os desafios advindos pelo envelhecimento, as mulheres lançam mão de estratégias como a grupalidade ou dos grupos de convivência. Estes são entendidos por seus integrantes como cenários de resgate da autoestima, ou de ressocialização, na medida em que a exclusão passa a fazer parte da vida de muitas delas. Nestes cenários chama atenção a maciça participação feminina. Os grupos funcionam como espaços no quais o idoso encontra proteção para as angústias decorrentes das perdas. As pessoas se identificam e, com isso, se deparam com coincidências, resgatam o desejo e a ilusão, reativam sua história. ${ }^{9}$

0 que acontece nos processos de grupo é revelador não só na obtenção dos objetivos a que se propõe o grupo como também das possibilidades de enfrentamento ativo do processo de envelhecimento, com o uso de ricos recursos pessoais nos seus diferentes aspectos biopsicossociais. ${ }^{10}$

Diante destas considerações, este estudo tem foco no evento grupalidade e, mais especificamente, no processo de reinserção de mulheres idosas em um grupo de convivência e, por meio deste movimento, na identificação do papel que este espaço social exerce na vida destas mulheres.

Para isso, os seguintes objetivos foram traçados: identificar a motivação que impulsiona mulheres idosas a procurarem grupos de convivência, analisar e pontuar a apreensão de estratégias por parte dos sujeitos que contribuam para a reelaboração e reinvenção de saberes e fazeres cotidianos geradores de ganhos de bem- estar.

0 envelhecimento humano é um evento das sociedades modernas e pós-modernas. Desta forma, as tentativas de compreensão das problemáticas que ele envolve contribuem para a revisão dos modelos de atenção vigentes, reelaborandoos no sentido de atender às reais necessidades e desejos desses indivíduos. Constrói-se, também, nas demais faixas etárias, outros modos de conceber o envelhecimento e modos de lidar com esses indivíduos, possibilitando que eles usufruam de seus direitos de cidadãos. 


\section{RECURSOS METODOLÓGICO}

Este estudo é parte integrante de um projeto mais amplo sobre estilo de vida de idosos no município de Niterói-RJ e obteve aprovação do Comitê de Ética em Pesquisa da Faculdade de Medicina/Hospital Universitário Antônio Pedro da Universidade Federal Fluminense (UFF) - Niterói/RJ pelo número 017/07.

Trata-se de uma pesquisa descritiva, exploratória, com abordagem qualitativa. 0 cenário foi o Projeto Gugu. Este é um espaço de convivência que atende aos quesitos de voluntariado, idealizado há 12 anos na cidade de Niterói-RJ por um profissional do campo da educação física conhecido como Carlos Augusto Bittencourt. 0 objetivo do Projeto é oferecer atividades físicas e lúdicas, gratuitamente, em espaços públicos. Com o crescimento do número de participantes foram sendo criados "Núcleos". Atualmente o Projeto conta com 27 Núcleos espraiados por diversos bairros da cidade. Participam, diariamente, por meio de exercícios orientados por profissionais, 1.700 pessoas, sendo a grande maioria delas de mulheres idosas. 0 Núcleo selecionado como cenário deste estudo foi 0 da "Praia de Icaraí", situado no bairro Icaraí - Niterói/ RJ. As atividades deste núcleo aconteciam no calçadão da praia de Icaraí de segunda a sexta- feira, de $7 \mathrm{~h}$ às 8 h e sábados e domingos de $8 \mathrm{~h} 30$ às $9 \mathrm{~h} 30$.

Para compor os sujeitos do estudo foram utilizados como critérios de inclusão ter mais de 60 anos e ser participante do Núcleo há mais de 1 ano. Foram, deste modo, selecionadas 14 mulheres idosas que atenderam ao quesitos de inclusão, sem distinção de classe social, cor, profissão e escolaridade. Os instrumentos utilizados para a coleta de dados foram entrevista semiestruturada e observação participante.

É importante destacar que a observação das atividades foi realizada em dias aleatórios e que as entrevistas foram realizadas minutos antes de ser iniciada a atividade do dia e em dias distintos. Para a realização das entrevistas não foram utilizados aparelhos gravadores, as falas eram transcritas pelo entrevistador à medida que se obtinham as respostas e, somente, após o consentimento e assinatura do termo de consentimento livre e esclarecido pelas mulheres do estudo.

A análise dos dados obedeceu à técnica de análise de discurso e aconteceu em dois momentos: Primeiramente foram analisados os dados gerados pela observação das atividades de grupo e, no segundo momento, aqueles oriundos das entrevistas. Após a análise dos depoimentos, estes foram agrupados de acordo com as semelhanças, gerando categorias as quais foram confrontadas com a literatura sobre o tema. Assim surgiram cinco categorias: Valorização e respeito ao idoso diante dos olhos: razões pela demanda ao grupo, na qual foi questionada o motivo dos sujeitos se inserirem no Núcleo; A busca de atividades geradoras do envelhecer saudável, em que foi indagado quais as atividades realizadas pelas mulheres $\mathrm{e}$ se elas contribuem em suas vidas; 0 projeto como espaço de revisão e de reelaboração do viver, na qual foi questionado se houve mudanças em suas vidas após a inserção no Projeto; Do espaço privado ao espaço público: ações femininas na desconstrução de preconceitos, em que se buscaram os motivos para a significativa demanda de mulheres pelos espaços públicos de atividades; e A interrelação entre idosas e atividades em grupo: os determinantes para a permanência no grupo, na qual foram identificados os motivos que implicam na permanência das idosas neste cenário.

\section{RESULTADOS E DISCUSSÃO}

\section{Sobre a Observação Participante}

0 cenário e os sujeitos selecionados para o presente estudo, como descrito anteriormente, integram o Projeto Gugu, um espaço de convivência aberto a indivíduos de diferentes idades, mas com um enfoque mais direcionado a indivíduos com mais de 60 anos. As atividades desenvolvidas diariamente são, em sua maioria, de exercícios aeróbicos - modalidade ginástica, e o local de sua realização é a calçada ampla ("calçadão") em frente à Praia de Icaraí, fato que permite o entrosamento com os transeuntes, já que é um lugar público e de grande circulação de pessoas. Todas as participantes vestem camisetas brancas com logomarca do Projeto Gugu. Já os professores vestem camisetas vermelhas com a mesma logomarca onde, também, está escrito a palavra professor, sendo esta uma maneira de diferenciar os participantes (ou alunos) dos professores.

Apesar de esse Núcleo só oferecer a modalidade de atividade ginástica, nada impede aos integrantes de participarem de outras atividades como aulas de teatro, dança de salão e coral, oferecidos em outros Núcleos, visto que um Núcleo mantém contato com outros e as atividades são amplamente divulgadas. Esta busca foi relatada por algumas das entrevistadas.

A atividade de ginástica é coordenada por diferentes professores a cada dia e, com isso, as estratégias são realizadas de maneiras distintas, de acordo com as especificidades de cada um deles. Cada professor tem um estilo próprio de conduzir a atividade. Alguns são mais alegres e descontraídos, enquanto outros destacam-se por conferir à atividade uma didática semelhante a aula ou seja, centrada na relação professor-aluno.

Foi observado que este Núcleo possui aproximadamente 50 mulheres, entre idosas e não idosas, todas elas cadastradas no Projeto Gugu. Mas, como a participação é livre e a frequência não é obrigatória, o número de participantes oscila muito, mas é mantida uma alta assiduidade. Cabe salientar que, no decorrer do período de observação, não houve nenhuma presença de idoso do sexo masculino e, deste modo, foi comprovado o processo de feminização das atividades neste Núcleo do Projeto Gugu.

Em cada encontro as idosas chegam já vestidas com 0 uniforme e se dispõem em fileiras, de forma a não atrapalhar a visão de cada participante em relação ao professor que se 
encontra a frente. Cada uma delas tem um lugar previamente demarcado, que passa a ser fixo após a seleção dele.

A interação está presente em cada momento; cada uma delas ajuda a outra a realizar os exercícios, corrigindo-se mutuamente se houver erros ou dificuldades. Assim, buscam a harmonia, a solidariedade e a compreensão das limitações individuais.

Antes de iniciar a atividade do dia é selecionada uma música por uma das integrantes, identificada pelas demais como representante do Núcleo. Esta representante estabelece o elo de ligação entre o Núcleo e a Fundação Carlos Augusto Bittencourt, responsável pelo Projeto Gugu.

As atividades iniciam com a chegada do professor que trás consigo as músicas selecionadas para serem tocadas. Estas começam e terminam, impreterivelmente, na hora exata, o que demonstrou ser uma atitude de respeito ao grupo. Cabe aqui um parêntese: este é um fato que as participantes lembraram em seus depoimentos como fundamental para a sua permanência no Núcleo.

No momento da realização das atividades era notório que todas as faziam com muita atenção e que este sempre representa um momento de interação e de descontração entre o professor e as participantes. Ao terminar, algumas logo se apressam para ir embora, outras aproveitam para conversar sobre diferentes assuntos, como trocar receitas caseiras, falar da família, entre outros. Outras se despedem dizendo que precisam aproveitar para realizar caminhada. Ficou evidenciado, em diferentes momentos, que a preocupação em resgatar ou manter uma vida saudável é o norte dos sujeitos do estudo.

$A$ assiduidade às atividades é um fato que chama a atenção. As ausências são reduzidas, e, quando isso acontece, logo as participantes observam e tentam descobrir o motivo da ausência das colegas. Comprova-se, assim, que os laços de amizade se estreitam de acordo com o tempo de frequência no grupo.

Um outro fato observado e que deve ser ressaltado diz respeito à autonomia de vida das participantes ao chegarem ao Núcleo. A grande maioria delas mostra-se independente. Raras foram aquelas que chegaram acompanhadas.

Todas se cumprimentam quando chegam e se despedem quando vão embora. Umas são mais extrovertidas do que outras, mas o clima de acolhimento chama a atenção.

Por vários momentos foi possível constatar que o clima predominante no Núcleo é o de amizade, de descontração, de companheirismo e muita alegria. As seguintes falas foram ouvidas por diversas vezes: Falar de doenças?! Nem pensar.... Aqui é lugar de se divertir e de se cuidar...

0 que elas deixaram evidenciado é o desejo de ser esta uma das formas de aproveitarem esta etapa da vida. Esses vínculos que elas vão construindo no Grupo contribuem para o que elas apontam como luta pelo ideal de "velhice com saúde". Nos grupos de terceira idade as pessoas organizam-se para fazer ginástica, dançar e cantar, para trocar experiências, como forma de lutar contra a estagnação social da velhice e de viver com saúde essas etapas da vida. ${ }^{11}$

0 perfil dos sujeitos participantes foi traçado a partir do levantamento das características das 14 mulheres idosas entrevistadas. Em relação à idade, a maioria estava na faixa etária entre 70 e 80 anos, o que leva a perceber que a própria população idosa em si está ficando mais velha. Dados de 1996 demonstram que o grupo etário de 65 a 74 anos (18,7 milhões) era oito vezes maior que em 1900, mas que o grupo etário de 75 a 84 anos (11,4 milhões) era 16 vezes maior. ${ }^{12}$

0 grande quantitativo de mulheres viúvas foi comprovado, corroborando os dados apresentados pelo Instituto Brasileiro de Geografia e Estatística. ${ }^{13}$ É possível dizer que "essa diferença no estado civil deve-se a diversos fatores: as mulheres apresentam uma expectativa de vida mais longa que os homens, as mulheres tendem a se casar com homens mais velhos e permanecem viúvas, enquanto os homens frequentemente voltam a se casar". 12:158

Em relação à escolaridade predominou, entre as entrevistadas, o nível fundamental incompleto. Este fato é o reflexo direto da história vivenciada pelas mulheres há décadas, quando suas funções ou papéis estavam restritos ao lar e para tais atividades não era necessário conhecimento formal. As mulheres idosas de hoje estão mais sujeitas a um risco para o funcionamento intelectual ineficiente do que os homens, não por fatores genéticos relacionados ao sexo, mas por geralmente terem tido menos oportunidades do que os homens de adquirirem conhecimentos formais, e este fato foi determinado por razões históricas e culturais. ${ }^{14}$

Quanto à localidade em que residem destaca-se a predominância do bairro Icaraí, região habitada, geralmente, por pessoas de classe média que possuem escolaridade diferenciadae um padrão de vida mais elevado, fatos esses que podem influenciar ou mesmo determinar o modo como as entrevistadas encaram o envelhecimento e os modos que buscam para vivê-lo.

Sobre o tempo de participação nas atividades oferecidas pelo Núcleo Praia de Icaraí ficou constatado o longo tempo de participação. Das 14 entrevistadas, 6 participam entre 1 e 5 anos; 3 , de 5 a 10 anos; e 5 estão há mais de 10 anos. Estes dados revelam que agrupando o intervalo acima de 5 anos obtém-se a maioria das participantes, ou seja, 08 . Deste modo percebem que "ações coletivas, quando canalizadas por objetivos reais e concretos, cumprem seu papel na construção da utopia do envelhecer saudável". 11:112

Ao encerrar o período da observação foi possível constatar e compreender que ações voluntárias como as que são desenvolvidas pelo Projeto Gugu estão cada vez mais sendo ofertadas a diferentes grupos sociais (destacando-se o de idosos), e estes vem conquistando espaço e credibilidade social. Todos estes movimentos buscam levar esses indivíduos à retomada de seu espaço social, à reconquista da autoestima reprimida em épocas passadas, reelaborando suas histórias de vida. 
grupo no cotidianos de mulheres idosos

Daher DV, Debona KV

\section{Sobre os discursos dos sujeitos}

Valorização e respeito ao idoso diante dos olhos: razões pela demanda ao grupo

Esta primeira categoria procurou entender os motivos que levaram as mulheres a buscarem o Projeto. A grande maioria das entrevistadas relatou se inserir de forma espontânea; ou seja, ao realizarem outras atividades tiveram a oportunidade de conhecer o trabalho do Projeto, o que despertou seu interesse e, consequentemente, gerou a identificação com ele. A fala a seguir ilustra este fato:

Quando eu morava no Bairro Cubango, a janela da minha casa dava para o lugar onde o Projeto Gugu fazia a ginástica. Eu via todo dia e daí comecei a ver o respeito e a valorização que era dada ao idoso. Aí eu decidi por conta própria começar a participar e daíme apaixonei... (E1)

No que diz respeito a esse tipo de motivação, pode-se afirmar que "os comportamentos intrinsecamente motivados são voluntários e independentes de recompensas materiais ou coações. 0 prazer ou satisfação derivam do desempenho em si. Os comportamentos intrinsecamente motivados são autogerados" $15: 66$.

A busca de atividades geradoras do envelhecer saudável

Esta categoria buscou identificar as atividades realizadas que são indicativas de mudanças ou reorientações do cotidiano. Ficou constatado que se busca uma diversidade de atividades e que estas influenciam ou contribuem na reordenação dos hábitos de vida tornando-os recompensadores, conforme mostra as falas a seguir:

Faço ginástica aqui do núcleo, dança de salão e pilates também! Essas atividades melhoram minha condição de saúde física e mental e contribuem para a minha qualidade de vida. (E2)

A ginástica aqui e a RPG [Reeducação Postural Global]. Elas me ajudam a levantar. Eu tenho problema na coluna. (E3)

Com o exposto é possível compreender que "a seleção de atividades concretas de tempo livre constitui um processo individual com amplas possibilidades de escolha pessoal, considerando-se os condicionamentos individuais e sociais, o que torna difícil generalizar os tipos de atividades" ${ }^{16: 221}$

0 projeto como espaço de revisão e de reelaboração do viver

Quando questionadas se ocorriam mudanças ou modificações em suas vidas após a busca e inserção no Projeto a grande maioria das entrevistadas respondeu que o Grupo funciona como espaço de reordenamento e redirecionamento da vida, conforme apontam as falas abaixo:
Muito para melhor! Eu era muito só e triste antes... e a convivência aqui me fez muito bem.(E4)

Eu me sinto melhor após iniciar aqui... me sinto bem com o pessoal, com as novas amizades.(E5)

Modificou em tudo! Nós somos uma nova familia!(E1)

0 Projeto é compreendido não apenas como mais um espaço de lazer, de passatempo diário, mas como espaço de possibilidade de ampliação de redes sociais e de resgate de um viver saudável. Nele ampliam-se os laços afetivos que implicam a própria reelaboração do sentido da existência.

Do espaço privado ao espaço público: ações femininas na desconstrução de preconceitos

Procurou-se entender nesse momento a predominância feminina no Grupo. Para as entrevistadas ela está relacionada à cultura ou ao conjunto de hábitos e costumes que regem as vidas de homens e mulheres nas sociedades. Ou seja, os espaços sociais estão claramente demarcados para homens e para mulheres. 0 cenário do Grupo é entendido como de e para mulheres, comprovado pelos discursos a seguir:

Onúmero de mulheres ébem maior. Aqui no nosso grupo só tem mulher, em outros tem alguns poucos homens, mas a maioria é de mulher. Eu acho que eles devem ter vergonha de fazer ginástica em grupo aberto. Falam que é coisa de mulher...(E2)

Sim! Eu acho que eles têm vergonha. Eles até têm vontade, mas têm vergonha. Meu marido é mesmo um que tem vontade. Se tivesse pelo menos um homem aqui ele viria...chamaria os outros, mas esse um nunca vem!(E4)

0 número de mulheres que participam de grupos é maior que o número de homens.

No Brasil, os programas para a terceira idade têm mobilizado, sobretudo, um público feminino. A participação masculina raramente ultrapassa os $20 \%$, e o entusiasmo manifestado pelas mulheres na realização das atividades propostas contrasta com a atitude de reserva e indiferença dos homens: ${ }^{4} 139$.

A interrelação entre idosas e atividades em grupo: os determinantes para a permanência no Grupo

Nesta categoria buscou-se entender que fatores estão envolvidos na permanência de cada um dos sujeitos no Grupo. Ficou comprovado que as atividades ofertadas e as relações sociais que se constroem influenciam diretamente na revisão de vida dos participantes. Sair de casa com propósito de manterem-se ativos é uma forma de estranhar o estabelecido e de negar os estereótipos construídos que tentam se perpetuar 
nas sociedades contemporâneas. Os depoimentos apontam neste sentido:

Eu acho que pra mim isso é vida... vir pra cá, conversar com as minhas amigas que fiz aqui, fazer ginástica $e$ ficar mais disposta. (E5)

A saúde né... os exercícios fazem bem para a saúde. O meu neurologista disse que tirei na loto por causa do meu derrame cerebral e não estar puxando a perna nem nada. (E6)

A atividade favorece a obtenção de satisfação pessoal para o idoso, uma vez que empresta significado à existência. Pode contribuir para a ocorrência de interação social significativa e para a profilaxia e cura do estresse. Através dela pode-se praticar a autodeterminação ${ }^{17: 70}$.

\section{CONSIDERAÇÕES FINAIS}

A longevidade é um desafio que vem se consolidando nas sociedades ocidentais contemporâneas, reconstruindo a própria história da humanidade. Uma das características marcantes deste processo de "geriatrização da sociedade" diz respeito ao percentual prevalente de mulheres nesse grupo social, como foi demonstrado neste estudo. Essa mudança na demografia mundial tem forçado as sociedades a reverem seus conceitos e a proporem políticas públicas que tratem desta questão e para que possam ofertar a esse grupo social condições para se manterem ativos e independentes o mais tempo possível.

Os movimentos por mudança nas concepções sobre o ser idoso estão em processo. Defende-se, em diferentes instâncias, que se viva mais e, sobretudo, com qualidade. Este é o pensamento dos idosos, fato que os impulsiona na busca de alternativas geradoras de uma velhice saudável. Exemplo de alternativa buscada por esses indivíduos são os grupos na medida em que as experiências coletivas se apresentam como canais de aprendizagem para a reconstrução de cidadania. ${ }^{11}$

0 estudo comprovou que a procura por grupos é crescente e que se dá de forma espontânea, o que aponta que os idosos vem se conscientizando de que viverão por mais tempo. Neste sentido, buscam reelaborar o viver, construindo meios para se manterem saudáveis, ativos e independentes, possibilitando desfrutar com prazer os anos a mais que a vida lhes reserva.

Dentro do grupo pesquisado, houve prevalência da presença feminina. A conquista pela liberdade feminina é, para elas, um fato irreversível e contribui, inclusive, para a redefinição do significado de envelhecimento. Os grupos são cenários nos quais se pode experienciar a criatividade, a autonomia e a liberdade e onde o respeito às limitações impostas pelo envelhecimento é incorporado como natural. Assim, compreendese que compartilhar o envelhecimento com o coletivo significa bem viver. As idosas participantes do Projeto estão inseridas em um processo no qual, ao mesmo tempo em que trabalham seus corpos, trocam experiências e novas aprendizagens, interiorizando questões coletivas como o cuidado de si diante do processo de envelhecimento.

Diante do relatado, fica comprovado o quanto é necessário e urgente um maior aprofundamento e socialização de pesquisas sobre esta temática, visto que através delas surgem contribuições importantes e criativas para os idosos, para as famílias e para a sociedade em geral. Estes estudos contribuem, de modo especial, para os profissionais envolvidos com esta clientela, visto que representam oportunidades para os mesmos reverem e redirecionarem suas práticas.

Somente através da compreensão do particular processo de envelhecimento e do devido respeito à pessoa idosa, entendendo-a como um indivíduo socialmente incluído, podem os mitos e preconceitos serem desconstruídos.

\section{REFERÊNCIAS}

1. Moreira MMS. Trabalho, qualidade de vida e envelhecimento [dissertação de mestrado]. Niterói (R)): Escola de Enfermagem Aurora de Afonso Costa, Universidade Federal Fluminense; 2000.

2. Beck CLC, Gonzáles RMB, Colomé IC dos S. Os desafios (IM) postos pelo processo de envelhecimento humano. Rev. Técnico-científica de Enf. 2003 mar/abr1(2): 122-26.

3. Santos, SP. Para onde foi o meu desejo sexual? A concepção da mulher idosa sobre sua sexualidade [trabalho de conclusão de curso]. Niterói (RJ): Escola de Enfermagem Aurora de Afonso Costa, Universidade Federal Fluminense, 2004.

4. Debert GG. A reinvenção da velhice: socialização e processo reprevatização do envelhecimento. São Paulo (SP): FAPESP; 1999.

5. Silva AL. 0 feminino pós- moderno e a pesquisa: implicações para a enfermagem. Texto\& Contexto Enferm1997 jan/abr; 6(1): 66-83.

6. Rocha CR, et al. A enfermagem e a saúde da mulher: questões de gênero e sociopolíticas. Esc Anna Nery 2000 abr; 4(1): 105-14.

7. Debona KV. A busca do viver saudável: o papel dos grupos de convivência no cotidiano de mulheres idosas [trabalho de conclusão de curso]. Niterói (RJ): Escola de Enfermagem Aurora de Afonso Costa, Universidade Federal Fluminense, 2007.

8. Lins JP. A vida que começa aos 60: o climatério e o envelhecimento sob o olhar de mulheres na terceira idade [trabalho de conclusão de curso]. Niterói (RJ): Escola de Enfermagem Aurora de Afonso Costa, Universidade Federal Fluminense, 2004.

9. Botelho TF. Terapia de grupo: a visão do idoso em depressão [trabalho de conclusão de curso]. Niterói (RJ): Escola de Enfermagem Aurora de Afonso Costa, Universidade Federal Fluminense, 2004. 
10. Vallois EA. Psicossomática e o câncer: reflexões sobre a grupoterapia numa visão transdisciplinar [trabalho de conclusão do curso de especialização]. Niterói (RJ): Escola de Enfermagem Aurora de Afonso Costa, Universidade Federal Fluminense, 2009.

11. Portella MR. Grupos de terceira idade: a construção da utopia do envelhecer saudável. Passo Fundo (RS): UPF; 2004.

12. Smeltzer SC, Bare BG. Brunner \& Suddarth: Tratado de enfermagem médico cirúrgica. Rio de Janeiro (RJ): Guanabara Koogan; 2002.

13. Instituto Brasileiro de Estatística e Geografia - IBGE [on-line]. [acesso 2006]. Disponível em: http://www.ibge.gov.br

14. Neri AL. Envelhecimento e qualidade de vida na mulher. Campinas (SP): Unicamp; 2001.

15. Deps VL. Atividade e bem-estar psicológico na maturidade. In: Neri AL, organizador. Qualidade de vida e idade madura. Campinas (SP): Papirus; 1993.

16. Moragas RM. Gerontologia social: envelhecimento e qualidade de vida. São Paulo (SP): Paulinas; 1997.

17. Neri AL. Qualidade de vida e idade madura. Campinas (SP): Papirus; 1993. 